\title{
NEW ALLIANCES
}

\author{
James Spigarelli, \\ President and CEO \\ Midwest Research Institute
}

Midwest Research Institute (MRI) has been in existence since 1944. One of the main objectives of our founding fathers was for MRI to make a positive economic impact on the Kansas City region. For the first ten years of operation MRI served as a research arm for many local companies, but we changed direction in the late 60's and early 70's as federal funding increased. By the early 80 's the federal government funded about $90 \%$ of our contract research. We have reversed that trend and now have about $30 \%$ of our contract work funded by private industry.

In 1977, we won the contract to manage the Solar Energy Research Institute, which later became the National Renewable Energy Laboratory for the Department of Energy. This is the premier laboratory for the federal government's funding of basic and applied research in renewable energy and energy efficient technologies. To win this contract initially we had to bid with a state. At that time, Kansas and Missouri didn't show much interest in furnishing a location for this laboratory, so it became located in Golden, Colorado. Today there is more awareness about the importance of research, development, and technology transfer to the economic health of a community. I'm confident that if the same opportunity presented itself today, the result would be much different, and the 1,000 high tech jobs that are located in Golden would be located somewhere in the Kansas City region.

The Kansas City Area Life Sciences initiative is an example of the value many groups place on research and technology in terms of the regional economy. This alliance includes research institutes, universities, and research hospitals along with civic organizations such as the Civic Council and the Kansas City Area Development Council. Today, Kansas City is creating its own roadmap to draw upon its strengths. Life sciences research and technology transfer will be an important part of its economic development over the next 10 to 20 years.

The kind of research that will make Kansas City successful is not described by a linear research model. Instead, use-directed fundamental research is what we need. Pasteur was interested in understanding fundamental issues, but he also wanted to apply the results for the good of society as quickly as possible. This is the goal in medical research. For 
example, researchers want to understand the mapping of the human genome and to make this knowledge work for the good of people. In Kansas City, if we receive public money, there will be pressure to realize an economic impact as quickly as possible. Alliances that achieve directed fundamental research make an impact on the community in the most rapid manner. We must talk about research in this way.

We have some unique advantages in Kansas City. Whatever we do, we must take these specific strengths into account. We must form alliances thoughtfully and according to criteria that will enhance our possibilities of success. If an alliance does not bring researchers together and make it easier for them to conduct research, it is not worth forming. There are several important criteria: 1) the leaders of the organizations must believe the alliance is important, 2) the organizations must have complementary core competencies, 3 ) there must be a market/societal need and clients for the core competencies, and 4) an effective infrastructure must be created. Recently MRI has formed several alliances that meet these criteria. For example, we are working with researchers and administrators at the University of Kansas Medical Center and at the Lawrence campus to define common areas of research and to develop an infrastructure that fosters collaboration between our institutions. We have a head start because we have carried out joint research projects in the past. We also have formed an alliance with Children's Mercy Hospital in Kansas City to develop new medicines for children. We formed this alliance because MRI has the analytical chemistry researchers and the instrumentation to complement the clinical and basic research capabilities at Children's Mercy. Both kinds of institutional alliances are designed to achieve synergies in breadth and quality of research and to remove institutional barriers that would hinder our work together.

The momentum created by the Kansas City Life Sciences Institute helped in forming these alliances and will make future alliances much easier. But research alliances are just part of what is necessary to make the Kansas City Area Life Sciences initiative work. William Brundage spoke about a business plan. We are preparing a strategic plan that will model the investment needed not only for R \& $D$ but also for education, technology transfer, and commercialization. We must create an infrastructure to support the creation of new companies that will add to the high technology job opportunities in our region.

The McKinsey group did a study for the city of Houston. Houston has about $\$ 400$ million in funded life sciences $R \& D$ annually, compared to San Diego, which has about $\$ 250$ million in funded life sciences R \& D. Yet, there were only three venture capital deals in Houston last year compared to about 70 in San Diego. If you don't have the capital, legal 
advice, and the CEO's to mentor start-up companies, you don't have the infrastructure in place to make an economic impact.

The Kansas City Area Life Sciences Institute represents a "grand alliance" among research organizations, foundations, and civic institutions. It will create synergistic collaboration, an infrastructure, and a source of funds to help each organization achieve what they couldn't achieve individually, and to help the community realize a strong, technology-based economy and better health care for its citizens. 